\title{
Approach to management of penile fracture- Our Three-year experience at a Teaching Hospital
}

\section{Sunil Basukala, Narayan Thapa, Bikash Bahadur Rayamajhi, Bikram Basukala, Saurav Karki}

\section{Abstract}

\section{Introduction}

Penile fracture is a rare surgical emergency. It usually occurs as a single rupture of the tunica albuginea in one of the two corpora cavernosa; a rupture of both masses is an uncommon finding. We conducted this study to determine the etiology, clinical presentation and to review the causes and management of penile fracture.

\section{Methods}

The retrospective study was carried out on 17 patients, admitted in the department of Urosurgery from January 2017 to December 2020 with penile fracture in a tertiary care teaching hospital in Kathmandu. Patient demographic profile, etiology, clinical presentation, time interval from injury to presentation, investigation done, treatment given and intraoperative findings were analyzed.

\section{Results}

The main cause of penile fractures was sexual intercourse $(82.35 \%)$ followed by manual manipulation (17.65\%). Crackling sound $(100 \%)$ followed by penile hematoma and pain were the most common presenting symptoms among the patients. Surgical exploration and repair of injury was done in all patients.

\section{Conclusion}

Most of the time diagnosis of penile fracture can be made reliably by history and physical examination. Early surgical intervention is associated with a good outcome, regardless of the timing of presentation.

Key words: Penile fracture; Sexual Intercourse; Tunica Albuginea.

\section{Author affiliations:}

Department of Surgery, Nepal Army Institute of Health Science (NAIHS), Sanobharyang, Kathmandu, Nepal.

\section{Correspondence:}

Dr. Sunil Basukala,

Department of Surgery, Nepal Army Institute of Health Science (NAIHS), Sanobharyang, Kathmandu, Nepal.

Email : anyurysm@gmail.com

ORCID ID:

https://orcid.org/0000-0001-9853-3160

Disclosures:

Ethical Clearance: IRB of NAIHS

Conflict of interest: None

Financial aid: None

Copyright information:

Authors retain copyright and grant the journal right of first publication with the work simultaneously licensed under Creative Commons Attribution License under CC-BY 4.0 that allows others to share the work with an acknowledgement of the works's authorship and initial publication of this journal.

\section{How to cite this article:}

Basukala S, Thapa N, Rayamajhi BB, Basukala B, Karki S. Approach to management of penile fracture- Our threeyear experience at a Teaching Hospital. J Soc Surg Nep. 2021 Jul; 24(1):10-3.

DOI:

https://doi.org/10.3126/jssn.v24i1.41029 


\section{Introduction}

Penile fracture is a rare presentation in Urosurgery with an incidence of 1 in $175,000 .{ }^{1}$ Penile fracture is defined as the traumatic rupture of the tunica albuginea of the corpora cavernous. ${ }^{2}$ The most common cause for penile fracture is sexual intercourse when the penis strikes the perineum or masturbation. Other causes include rolling over in bed on to the erect penis, forced flexion to achieve detumescence and external blunt trauma. ${ }^{3}$

The patient gives a classic history of hearing a crackling noise during sexual activity when the tunica ruptures, rapidly followed by pain, detumescence, and a substantial subcutaneous hematoma leading to an 'eggplant deformity' (Figure 1). ${ }^{4,5}$ Synchronous urethral injury could be present in $1 \%$ to $38 \%$ of cases which should be suspected in the presence of voiding symptoms, bleeding per urethra and haematuria. ${ }^{6}$

Historically, penile fracture was managed conservatively, but owing to its relatively high morbidity resulting in erectile dysfunction (ED), plaques, painful erections, curvature and infected hematomas ranging upto $30 \%$, surgical exploration with repair of corpus cavernosa is considered a standard mode of management in recent days. ${ }^{7-9}$ Immediate surgical intervention has also been associated with adequate functional and cosmetic results, with minimal complications. ${ }^{10-13}$

\section{Methods}

This was a retrospective study done in Shree Birendra Hospital, which is a tertiary level teaching hospital in Kathmandu, Nepal. Seventeen patients who presented with penile fracture over the period of three years, between January 2017 and December 2020 were included in this study. Patient details which included age, marital status, etiology, clinical presentation, time interval from injury to presentation, investigation done, treatment given, intraoperative findings, voiding symptoms and erectile function were collected from case sheet from the hospital records. The International Index of Erectile Function (IIEF 5) was used for grading of Erectile Dysfunction (ED) during their follow up. It is a five-item questionnaire used as a diagnostic tool for ED. The possible scores for the IIEF-5 range from 5 to 25 , and ED was classified into five categories based on the scores: severe (5-7), moderate (8-11), mild to moderate (12-16), mild (17-21), and no ED (22-25). Statistical analysis was performed by using the IBM SPSS version 24.0. The study was approved by the Ethics Committee of Nepal Army Institute of Health Sciences (NAIHS).

\section{Surgical procedure:}

All seventeen patients who presented with penile fracture underwent surgical repair. The surgical procedure consisted of a distal sub-coronal incision, with penile degloving and exposure of the corpora cavernosum, Corpus spongiosus and urethra. Urethral catheterization (14F-16F Foley catheter) was routinely performed, except for the cases where a urethral injury was suspected. Four cases with suspected urethral injury underwent cystoscopy prior to surgery within the same setting; however, no urethral injury was identified in these cases. A thorough inspection of all three corporeal bodies was performed after degloving the penile shaft (Figure 2). A rent beneath the Buck's fascia was identified (Figure 3). Corpora cavernosa lesions identified during surgical exploration were treated by interrupted polyglactin 3-0 sutures (Figure 4). Bladder catheter was maintained for 48 postoperative hours (Figure 5). Patients also received oral ketoconazole $400 \mathrm{mg}$ thrice a day and oral diazepam $5 \mathrm{mg}$ for two weeks to avoid painful erections. Patients were discharged on oral antibiotics for seven days and were advised to abstain from sexual intercourse for six to eight weeks.

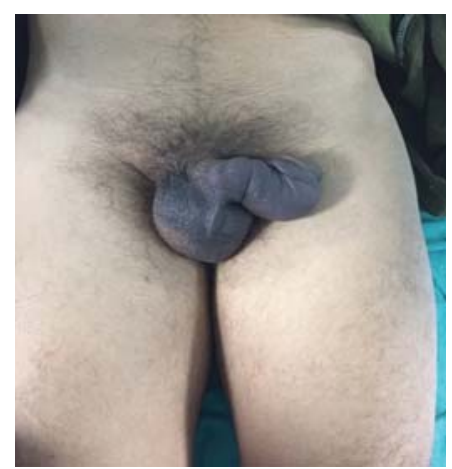

Figure 1. Penile deformity in a patient with penile fracture ("eggplant" deformity).

\section{Results}

Seventeen patients were included in this study. The mean age was 34.35 years (25-45 years). Among them, 12 patients $(70.5 \%)$ were married and $05(29.5 \%)$ were single at the time of presentation. The time interval from injury to presentation was 11.66 hours (6- 32 hours). Most common cause of injury was vigorous sexual intercourse in $(82.35 \%)$ followed by manipulation during masturbation in 02 cases $(17.65 \%)$. Almost all the patients presented with the typical clinical picture of a characteristic sound "crackling sound" at the time of injury followed by significant hematoma, pain and detumescence (Table 1). Hematoma was present in all the cases during presentation. Penile shaft Ultrasonography (USG) was done in all cases for confirmation of diagnosis which showed defect in the tunica albuginea in 15 cases while in two cases it showed hematoma with failure to show any defect in the tunica albuginea.

Table 1. Symptoms and signs in patients with penile fractures

\begin{tabular}{|c|c|c|c|}
\hline S.no & $\begin{array}{l}\text { Symptoms and } \\
\text { signs }\end{array}$ & Number & Percentage $(\%)$ \\
\hline 1. & Penile hematoma & 17 & 100 \\
\hline 2. & Pain & 07 & 41 \\
\hline 3. & Detumescence & 08 & 47 \\
\hline 4. & Crackling sound & 17 & 100 \\
\hline 5. & Urethral bleeding & 04 & 23.5 \\
\hline
\end{tabular}




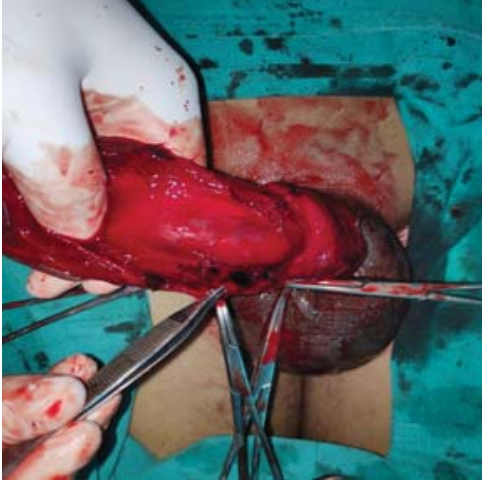

Figure 2. Degloving of the shaft of injured penis

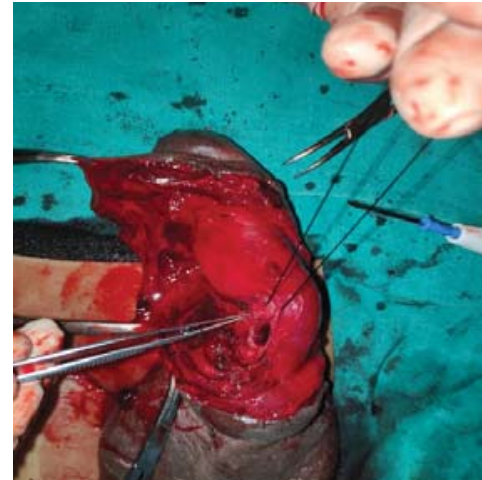

Figure 3. Rent in the tunica albuginea in the ventral shaft

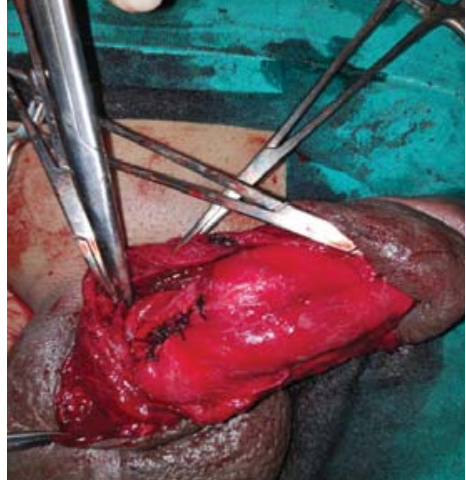

Figure 4. Repair of tunica albuginea with 3-0 polyglactin
Intraoperatively, penile fracture was found in all the cases. However, no urethral injury was found in this study. Among the injury the mean size of rent in corpora cavernosa was $1.75 \pm 1.0 \mathrm{~cm}$. Circumcision was done in all cases in which circumcoronal incision was used. Minor postoperative complications such as discoloration of skin and serous discharge were noted in two patients in immediate postoperative period which were managed conservatively. The mean hospital stay among these patients ranged between $4.15 \pm 2.5$ days (3-6 days). Erectile function test among these patients was done during the follow up period of three months, however, none of the patient showed Erectile Dysfunction (IIEF-5 $>22$ ).

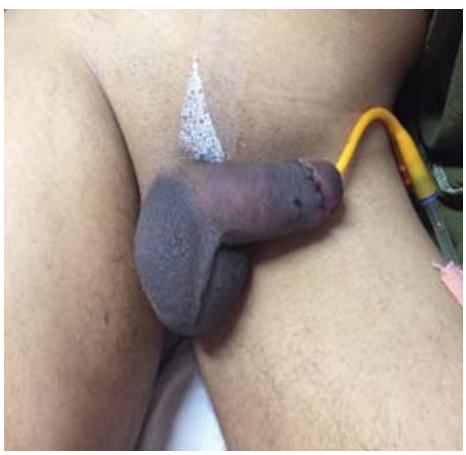

Figure 5. After 48 hours, the penile appearance is normal

\section{Discussion}

Penile fracture remains a rare surgical emergency worldwide, ${ }^{10-13}$ with an incidence of 1 in $175,000 .{ }^{1}$ It occurs when the penis is erect because the tissue of the tunica albuginea is thinner during erection and is vulnerable to a sudden increase in the intracorporeal pressure. The urethra and corpus spongiosum may also be affected. ${ }^{14-16}$ Emergency department physicians need to be aware of the urgency in the diagnosis of this condition and in the initiation of treatment as any delay increases the risk of complications. Due to the embarrassment associated with such injuries the patients may hesitate to disclose their complaint and delay seeking medical treatment. ${ }^{6}$
The mean age of presentation of patients with penile fracture in our study was 34.35 years with $12(70.5 \%)$ of patients being married. These findings were similar to study conducted by Nason et al among 21 cases of penile fracture. ${ }^{7}$ Among the cases reported for penile fracture, the most common cause is intercourse, ${ }^{6-10}$ but traumas to a tumescent shaft such as masturbation, habit of forcibly bending the erect penis to pass urine or rolling onto an erect penis have also been reported..$^{12}$ Sexual intercourse was the leading cause of penile fracture, accounting for $83.33 \%$ in our study followed by manipulation during masturbation and trauma. It remains the most common etiology in penile fracture ranging upto $95.23 \%$ as shown by few other studies. ${ }^{7,8}$ Majority of the cases in our study presented with hematoma of the penile shaft $(100 \%)$ and followed by pain and detumescence. These finding were similar to studies conducted by Swanson et al which showed that penile hematoma and history of crackling sound during penile manipulation was a consistent finding in almost all the cases presented with penile fracture. ${ }^{8}$

The diagnosis of penile fracture is mainly based on history and physical examination. ${ }^{17}$ The patient typically presents with a sharp cracking sound in the erect penis followed by rapid detumescence. ${ }^{6,7}$ The findings at presentation can include swelling of the penis, ecchymosis and deviation of the penis to the opposite side. ${ }^{12}$ Penile Ultrasound has been an easily available, non-invasive modality which quickly determines the site and length of injury in most of the cases. There is an interruption of the thin echogenic line of the tunica albuginea with associated hematoma suggestive of penile fracture. ${ }^{11,12}$ Absence of loss of the continuity of tunica albuginea in ultrasound however does not always rule out penile fracture. ${ }^{6}$ In our study, USG correctly diagnosed $15(88.2 \%)$ of the cases with suspected penile fracture. This percentage is however less compared to few other studies compared to De Luca et al $(97.43 \%)$ and Shukla et al (100\%). ${ }^{9,18}$

In our study, none of the patients had urethral injury intraoperatively. Since, we did not routinely perform urethrography in our patients, minor injuries resulting in hematuria could have been healed with short-term urethral 
catheterization. This finding was similar to the study done by Özorak A et al who conducted a retrospective study among 31 patients with penile fracture that showed no urethral injury though $33 \%$ of patients presented with hematuria on initial presentation. ${ }^{17}$

Treatment of penile fracture had been a controversial issue. Conservative management such as bed rest, pressure dressings, catheterization, and ice packs for 24-48 hours in addition to antibiotics, fibrinolytics, estrogens, and diazepam were used earlier. However, ten to thirty percent of patients receiving such conservative management developed impaired erections, permanent deformity, or suboptimal coitus. ${ }^{8-10}$ Immediate surgical intervention was done among all the patients regardless of the timing of presentation to the hospital in our study which showed lower incidence of erectile dysfunction and less chances of long-term penile curvature with greater patient satisfaction.

\section{References}

1. Koifman L, Barros R, Junior RAS, Cavalcanti AG, Favorito LA. Penile fracture: diagnosis, treatment and outcomes of 150 patients. Urology. 2010 Dec;76(6): 1488-92.

2. Ateyah A, Mostafa T, Nasser TA, Shaeer O, Hadi AA, Al-Gabbar MA. Penile fracture: surgical repair and late effects on erectile function. J Sex Med. 2008 Jun;5(6):1496-502.

3. Reis LO, Cartapatti M, Marmiroli R, de Oliveira Junior EJ, Saade RD, Fregonesi A. Mechanisms predisposing penile fracture and long-term outcomes on erectile and voiding functions. Adv Urol. 2014;2014 Apr;10(5):768-72.

4. Penbegul N, Bez Y, Atar M, Bozkurt Y, Sancaktutar AA, Soylemez H, et al. No evidence of depression, anxiety, and sexual dysfunction following penile fracture. Int J Impot Res. 2012 Jan;24(1):26-30.

5. Thompson RF. Rupture (fracture) of the penis. J Urol. 1954 Feb;71(2):226-9.

6. Ahmadnia H, Rostami MY, Kamalati A, Imani MM. Penile fracture and its treatment: is retrograde urethrograghy necessary for management of penile fracture? Chin J Traumatol. 2014 Dec;17(6):338-40.

7. Nason GJ, McGuire BB, Liddy S, Looney A, Lennon GM, Mulvin DW, et al. Sexual function outcomes following fracture of the penis. Can Urol Assoc J. 2013 Jul-Aug;7(7-8):252-7.

8. Swanson DE, Polackwich AS, Helfand BT, Masson P, Hwong J, Dugi DD, et al. Penile fracture: Outcomes of early surgical intervention. Urology. 2014 Nov;84(5):1117-21.

9. De Luca F, Garaffa G, Falcone M, Raheem A, Zacharakis E, Shabbir M, et al. Functional outcomes following immediate repair of penile fracture: A tertiary referral centre experience with 76 consecutive patients. Scand J Urol. 2017 Apr;51(2):170-5.

10. Kati B, Akin Y, Demir M, Boran OF, Gumus K, Ciftci $\mathrm{H}$. Penile fracture and investigation of early surgical
Early surgical treatment has been strongly recommended by the studies because of the excellent results, shorter hospitalization, less morbidity, and early return to full sexual activity. ${ }^{18-20}$

\section{Conclusion}

Penile fracture though rare, is an Urosurgical emergency. Thorough history and clinical examination are needed for making a diagnosis for most of the times. Our study showed that immediate surgical repair regardless of the timing of presentation is associated with faster recovery; avoids deformity, impaired erections and increases patient satisfaction.

\section{Acknowledgement:}

I would like to acknowledge the patients and the operating staffs of Shree Birendra Hospital for helping me prepare this research study.

repair effects on erectile dysfunction. Urologia Journal. 2019 Nov;86(4):207-10.

11. Agarwal MM, Singh SK, Sharma DK, Ranjan P, Kumar S, Chandramohan V, et al. Fracture of the penis: A radiological or clinical diagnosis? A case series and literature review. Can J Urol. 2009 April;16(2):4568-75.

12. Jack GS, Garraway I, Reznichek R, Rajfer J. Current treatment options for penile fractures. Rev Urol. 2004 Jan;6(3):114-20.

13. Yamaçake KG, Tavares A, Padovani GP, Guglielmetti GB, Cury J, Srougi M. Long-term treatment outcomes between surgical correction and conservative management for penile fracture: Retrospective analysis. Korean J Urol. 2013 Jul;54(7):472-6.

14. Mirzazadeh M, Fallahkarkan M, Hosseini J. Penile fracture epidemiology, diagnosis and management in Iran: A narrative review. Transl Androl Urol. 2017 Apr;6(2):158-66.

15. Kowalczyk J, Athens A, Grimali A. Penile fracture: an unusual presentation with lacerations of bilateral corpora cavernosa and partial disruption of the urethra. Urology. 1994 Oct;44(4):599-601.

16. Fergany AF, Angermeier KW, Montague DK. Review of Cleveland Clinic experience with penile fracture. Urology. 1999 Aug;54(2):352-5.

17. Özorak A, Hoscan MB, Oksay T, Güzel A, Kosar A. Management and outcomes of penile fracture: 10 years' experience from a tertiary care center. Int Urol Nephrol. 2014 Mar;46(3):519-22.

18. Shukla AK, Bhagavan BC, Sanjay SC, Krishnappa N, Sahadev R, V S. Role of ultrasonography in grading of penile fractures. J Clin Diagn Res. 2015 Apr;9(4):TC01-03.

19. Fetter TR, Gartmen E. Traumatic rupture of penis: Case report. Am J Surg. 1936 May;32(2):371-2.

20. Atat RE, Sfaxi M, Benslama MR, Amine D, Ayed M, Mouelli SB, et al. Fracture of the penis: management and long-term results of surgical treatment. Experience in 300 cases. J Trauma. 2008 Jan;64(1):121-5. 